\title{
Levels of exhaled nitric oxide before and after surgical and transcatheter device closure of atrial septal defects in children
}

Tilman Humpl, $\mathrm{MD}^{\mathrm{a}, \mathrm{e}}$

Rosalie Campbell, MBBCH ${ }^{\mathrm{d}, \mathrm{e}}$

Derek Stephens ${ }^{\mathrm{h}}$

Glen Van Arsdell, MD ${ }^{b, f}$

Lee N. Benson, $M D^{\mathrm{a}, \mathrm{c}}$

Helen M. Holtby, MBBS ${ }^{d}$

Arthur S. Slutsky, $\mathrm{MD}^{\mathrm{g}}$

Ian Adatia, MB, $\mathrm{ChB}^{\mathrm{a}, \mathrm{c}, \mathrm{e}}$
From the Divisions of Cardiology ${ }^{\mathrm{a}}$ and Cardiovascular Surgery ${ }^{\mathrm{b}}$ and the Departments of Pediatrics, ${ }^{\mathrm{c}}$ Anesthesia, ${ }^{\mathrm{d}}$ Critical Care Medicine, ${ }^{\mathrm{e}}$ Surgery, ${ }^{\mathrm{f}}$ Respiratory Medicine, ${ }^{\mathrm{g}}$ and Population Health Sciences, ${ }^{\mathrm{h}}$ Toronto Hospital for Sick Children and University of Toronto, Toronto, Ontario, Canada.

Received for publication June 11, 2001; revisions requested Aug 6, 2001; revisions received Oct 17, 2001; accepted for publication Oct 22, 2001.

Address for reprints: Ian Adatia, MB, ChB, Department of Critical Care Medicine, The Hospital for Sick Children, 555 University Ave, Toronto, Ontario M5G 1X8, Canada (E-mail: ian.adatia@sickkids.ca).

J Thorac Cardiovasc Surg 2002;124:806-10

Copyright () 2002 by The American Association for Thoracic Surgery

$0022-5223 / 2002 \$ 35.00+0 \quad \mathbf{1 2 / 1 / 1 2 1 3 0 1}$

doi: $10.1067 / \mathrm{mtc} .2002 .121301$
Objectives: We have shown that exhaled nitric oxide levels decrease after surgical closure of congenital left-to-right cardiac shunts. It remains unclear whether the change in exhaled nitric oxide levels reflects endothelial injury caused by the use of cardiopulmonary bypass or the decrease in pulmonary blood flow attendant on shunt closure. Transcatheter atrial septal defect closure permits shunt closure without the use of cardiopulmonary bypass. Therefore we compared changes in exhaled nitric oxide levels after surgical and transcatheter device closure of atrial septal defects.

Methods: We enrolled sequentially 30 children undergoing atrial septal defect closure. Fifteen patients (age range, 0.4-16 years; median age, 6.5 years) underwent surgical atrial septal defect closure with cardiopulmonary bypass, and 15 patients (age range, 4-17 years; median age, 8.4 years) had device closure of the atrial septal defect in the catheterization laboratory. We measured nitric oxide levels in end-tidal expiratory gas with a rapid-response chemiluminescent analyzer before and after atrial septal defect closure.

Results: After surgical repair of the atrial septal defect, exhaled nitric oxide decreased by $21 \%$, from $10.9 \pm 4.4$ to $8.4 \pm 3.3 \mathrm{ppb}(P<.005)$, whereas after transcatheter defect closure, exhaled nitric oxide increased by $23 \%$, from $7.6 \pm 2.6$ to $9.3 \pm 3.7 \mathrm{ppb}(P<.005)$. Hemoglobin levels in patients undergoing surgical intervention were significantly lower $(P=.0001)$ postoperatively.

Conclusions: We confirmed that exhaled nitric oxide, despite a fall in hemoglobin, decreases after surgical closure of atrial septal defects. In contrast, exhaled nitric oxide levels increase after transcatheter closure. Exhaled nitric oxide levels may reflect bypass-induced endothelial cell injury and are independent of changes in pulmonary blood flow.

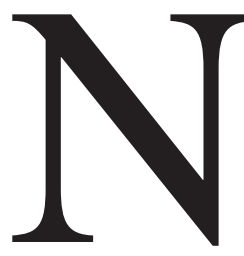

itric oxide (NO), synthesized by the vascular endothelium, plays a central role in the regulation of pulmonary vascular tone before and after correction of congenital heart defects. ${ }^{1,2}$ The pulmonary vascular endothelium may be injured by the shear stress imposed by congenital left-to-right shunts or cardiopulmonary bypass (CPB) necessary for the surgical repair. Endothelial injury and impaired production of NO may be implicated in the increased pulmonary vascular resistance encountered after $\mathrm{CPB} .^{2}$ This may explain the efficacy of inhaled NO in the treatment of pulmonary hypertension and reperfusion injury. ${ }^{1,3}$ We have dem- 
TABLE 1. Patient details

\begin{tabular}{lcc}
\hline & Transcatheter ASD closure $(\mathbf{n}=\mathbf{1 5})$ & Surgical ASD closure (n= 15) \\
\hline Age $(\mathrm{y})$ & Median 8.4 (range 4-17) & Median 6.5 (range 0.4-16) \\
Weight $(\mathrm{kg})$ & Median 23.5 (range 16-91) & Median 20 (range 5.2-57) \\
Sex & 6 male/9 female & 4 male/11 female \\
ASD size (cm) & Median 1.4 (range 0.8-1.9) & Median 1.6 (range 0.8-3.0) \\
\hline
\end{tabular}

No statistically significant difference in age, weight, or ASD size between groups was seen.

onstrated previously that exhaled NO levels decrease after surgical closure of left-to-right intracardiac shunts in children. ${ }^{4}$ The decrease in exhaled NO could reflect either CPB-induced endothelial cell injury or a decrease in pulmonary blood flow consequent on shunt closure.

Transcatheter device closure of atrial septal defects (ASDs) makes it possible to close intracardiac shunts without the use of CPB and thus discriminate between the effect of $\mathrm{CPB}$ and changes in pulmonary blood flow. Therefore we compared exhaled NO levels before and after ASD closure in patients scheduled for surgical or transcatheter ASD closure.

\section{Patients and Methods}

We enrolled sequentially 30 children (Table 1) with ASDs undergoing surgical closure with CPB $(n=15)$ or by means of device closure $(n=15)$ in the catheterization laboratory. The method of ASD closure was decided by the referring cardiologist after discussion with the family. However, 6 patients were referred for surgical ASD closure for reasons that excluded transcatheter ASD closure. Three patients had isolated primum ASDs, 2 patients weighed less than $10 \mathrm{~kg}$, and 3 patients had defects considered unsuitable for transcatheter closure at the time (1 patient had a fenestrated defect, in 1 patient the ASD was $20 \mathrm{~mm}$, and in 1 patient the rim of the ASD was considered too deficient). No patient was treated with glucocorticosteroids, nitrovasodilators, L-arginine, or inhaled or intravenous NO synthase inhibitors known to affect NO metabolism before or during the procedure. Anesthetic management included the administration of thiopentone, fentanyl, midazolam, muscle relaxants, and $1 \%$ isoflurane. The isoflurane was interrupted for 15 minutes before sampling for exhaled NO. The differences between the drugs administered to the surgical ASD closure group were muscle relaxation with pancuronium (vs rocuronium) and higher doses of fentanyl (12 \pm 8 vs $3 \pm 3 \mu \mathrm{g} / \mathrm{kg})$ and protamine.

Ventilator settings were kept constant before and after ASD closure, and the fraction of inspired oxygen was adjusted to between 0.25 and 0.3 for 15 minutes before NO sampling.

\section{Surgical Closure}

All patients received $300 \mathrm{U} / \mathrm{kg}$ heparin. CPB was performed with systemic cooling between $32^{\circ} \mathrm{C}$ and $35^{\circ} \mathrm{C}$ with bicaval and ascending aorta cannulation. Cool cardioplegia was administered through the aortic root in 11 cases performed with myocardial arrest. ASD closure was performed with ventricular fibrillation in 4 cases. Thirteen ASDs were closed with a patch, and 2 were closed by means of direct suture.
Exhaled gas samples were collected immediately before cannulation and 30 minutes after discontinuation of CPB. Arterial blood gas levels (including $\mathrm{pH}, \mathrm{PO}_{2}$, and $\mathrm{PCO}_{2}$ ), end-tidal carbon dioxide (except during sampling times), hemoglobin levels, heart rate, systemic blood pressure, and rectal temperature were measured at the same time points.

\section{Cardiac Catheterization}

Transcatheter ASD closure was accomplished through the femoral vein by using CardioSeal (NMT Medical, Inc, Boston, Mass) in 5 patients and Amplatzer Septal Occluder (AGA Medical Corp, Golden Valley, Minn) in 10 patients. All patients received 150 U/kg heparin. Hemoglobin levels were not measured after ASD closure in this study. However, during a separate pilot study, hemoglobin levels were measured in 6 consecutive patients before and after ASD device closure.

Samples of exhaled air in patients undergoing closure of the ASD in the cardiac catheterization laboratory were obtained before and 30 minutes after the intervention.

\section{Exhaled Gas Analysis}

Exhaled air was sampled with a 19-gauge, 12-inch catheter (Becton Dickinson Vascular Access, Sandy, Utah) tailored to the length of the endotracheal tube and inserted through the end-tidal carbon dioxide port. Two consecutive samples of end-tidal expiratory gas were drawn through the intratracheal catheter into a $20-\mathrm{mL}$ syringe to minimize airway NO uptake and approximate alveolar NO levels. Analysis of the specimen was performed with a rapidresponse chemiluminescent analyzer (Sievers 270B, Boulder, Colo). Calibration of the analyzer was performed daily with serial dilutions of a standard $\mathrm{NO}$ gas.

Ambient air in the operating and cardiac catheterization rooms measured $2 \mathrm{ppb}$ NO. Exhaled NO in the sealed syringes were determined within 15 minutes of sampling. We verified that this technique correlated $( \pm 5 \%)$ with immediate chemiluminescence measurement, providing samples were analyzed within 1 hour. The mean of the 2 samples was used for analysis.

All patients were assessed before and after ASD closure by means of 2-dimensional transesophageal or transthoracic echocardiography (pulsed and color flow Doppler examination). Mean pulmonary artery pressure was estimated from the peak velocity of the pulmonary insufficiency Doppler signal plus an assumed right atrial pressure of $5 \mathrm{~mm} \mathrm{Hg}$.

\section{Ethical Approval}

The research protocol was approved by the Hospital for Sick Children Human Ethics Committee, and informed consent was obtained from the subjects or their parents. 

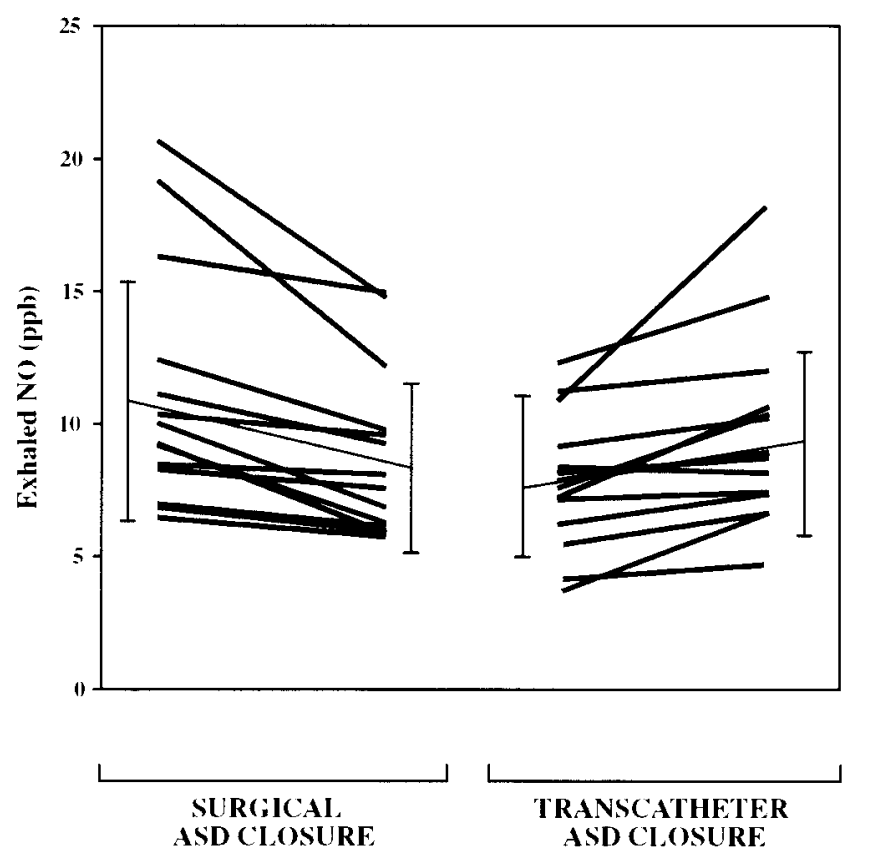

Figure 1. Exhaled NO before and after surgical and transcatheter ASD closure. Thick black lines, Individual measurements; thin black lines, means \pm SD.

\section{Statistical Analysis}

Continuous variables were expressed as means \pm SD. Withingroup differences were assessed with paired $t$ tests. The differences between the groups were assessed by comparing the difference or differences between before and after levels of NO. Analysis of covariance with adjustment for the preintervention level was used to compare the percentage change between groups.

Nonparametric testing was used to compare age, weight, and ASD size between the 2 groups because the data were not normally distributed. These results were expressed as medians and ranges.

\section{Results}

The individual measurements for each patient are shown in Figure 1. In patients undergoing surgical ASD closure, exhaled NO decreased by $21 \%$, from $10.9 \pm 4.4$ to $8.4 \pm$ $3.3 \mathrm{ppb}(P<.005)$. In contrast, there was a $23 \%$ increase in exhaled NO, from $7.6 \pm 2.6$ to $9.3 \pm 3.7 \mathrm{ppb}(P<.005)$, in the patients undergoing ASD device closure. Comparison of the percentage change in exhaled NO levels between transcatheter and surgical ASD closure was significantly different $(P<.0001)$.

The preintervention exhaled NO levels were significantly higher $(P<.05)$ in the surgical compared with in the transcatheter closure group. However, even with adjustment for the difference in baseline exhaled NO levels, there remained a significant difference $(P<.0001)$ in the postintervention exhaled NO level between the groups.

$\mathrm{CPB}$ time ranged from 14 to 81 minutes (median, 45 minutes; mean, $44.3 \pm 18.4$ minutes).
Hemoglobin levels in patients undergoing surgical intervention were significantly lower $(P=.0001)$ postoperatively (Table 2). Hemoglobin levels were not measured after transcatheter ASD closure in this study. However, there was no change in hemoglobin levels before (mean, $123 \pm 9.4$ $\mathrm{g} / \mathrm{L}$ ) and after (mean, $122 \pm 9.0 \mathrm{~g} / \mathrm{L}$ ) device closure in a different group of patients $(n=6)$. There were no statistically significant differences between systolic and diastolic blood pressure, $\mathrm{pH}, \mathrm{PCO}_{2}, \mathrm{Po}_{2}$, and end-tidal carbon dioxide between the 2 groups (Table 2).

Heart rate in patients after device closure of the ASD was slower compared with the initial values and with the heart rate at the end of the surgical procedure (Table 2).

Body temperature was lower in the surgical group (Table 2).

The mean pulmonary artery pressure estimated by means of echocardiography before and after ASD closure was similar in both groups $(15 \pm 4 \mathrm{~mm} \mathrm{Hg}$ before and $14 \pm 5$ $\mathrm{mm} \mathrm{Hg}$ after closure). Echocardiography revealed no residual shunt at the end of the operation. A trivial leak across the device was detected by means of color Doppler scanning in 3 of 15 patients after transcatheter closure.

\section{Discussion}

We found that exhaled NO levels decrease in children after surgical ASD closure undertaken with $\mathrm{CPB}$, despite the fall in hemoglobin. In contrast, transcatheter ASD closure results in an increase in exhaled NO levels. We suggest that endothelial cell dysfunction, rather than the decrease in pulmonary blood flow after ASD closure, is responsible for decreased NO production after CPB.

Endogenous NO production after $\mathrm{CPB}$ is decreased in lambs, piglets, and human subjects. ${ }^{5-7}$ Decreased exhaled NO levels after hypothermic CPB have been described in adults, as well as in children, after correction of left-to-right shunts. Thus our findings are in agreement with those of previous studies. ${ }^{4,7}$

Exhaled NO levels may decrease as a result of reduced NO production or increased NO inactivation. The present study can not differentiate between these 2 mechanisms. However, there is evidence that CPB adversely affects endothelial-dependant vasorelaxation and that endothelial dysfunction contributes to postoperative pulmonary hypertension and microvascular injury that is ameliorated by the postoperative use of inhaled NO. ${ }^{1,3}$ The possible contribution of hypothermia and the heparin-protamine interaction on exhaled NO levels can not be differentiated from CPB in the present study.

Hemoglobin decreased after surgical ASD closure. Exhaled NO levels increased in exsanguinated rats, and conversely, addition of autologous blood to a Krebs-dextran and albumin perfusion solution decreased exhaled NO in isolated pig lungs. ${ }^{8,9}$ The changes that we detected in exhaled NO are more compelling because the decrease after 
TABLE 2. Physiologic parameters before and after ASD closure

\begin{tabular}{lcccc}
\hline & Before CPB & After CPB & Before device & After device \\
\hline Hemoglobin $(\mathrm{g} / \mathrm{L})$ & $123 \pm 10$ & $88 \pm 12$ & $110 \pm 9$ & $\mathrm{NA}$ \\
Rectal temperature $\left({ }^{\circ} \mathrm{C}\right)$ & $35.9 \pm 0.7^{*}$ & $35.4 \pm 0.7^{*} \dagger$ & $36.4 \pm 0.4$ & $36.5 \pm 0.7 \dagger$ \\
Heart rate (beats/min) & $112 \pm 16$ & $115 \pm 19 \dagger$ & $105 \pm 21^{*}$ & $93 \pm 16^{*} \dagger$ \\
Systolic blood pressure $(\mathrm{mm} \mathrm{Hg})$ & $97 \pm 11$ & $98 \pm 15$ & $103 \pm 7$ & $102 \pm 10$ \\
Diastolic blood pressure $(\mathrm{mm} \mathrm{Hg})$ & $58 \pm 9$ & $55 \pm 10$ & $7.38 \pm 0.02$ & $\mathrm{NA}$ \\
$\mathrm{pH}$ & $7.42 \pm 0.07$ & $7.44 \pm 0.04$ & $41 \pm 5$ & $\mathrm{NA}$ \\
$\mathrm{Po}_{2}(\mathrm{~mm} \mathrm{Hg})$ & $235 \pm 114$ & $229 \pm 93$ & $37 \pm 4$ & $\mathrm{NA}$ \\
$\mathrm{PcO}_{2}(\mathrm{~mm} \mathrm{Hg})$ & $37 \pm 6$ & $38 \pm 4$ & $37 \pm 3$ & $37 \pm 4$ \\
$\mathrm{EtcO}_{2}(\mathrm{~mm} \mathrm{Hg})$ & $38 \pm 4$ & 37 &
\end{tabular}

Values are given as means $\pm \mathrm{SD}$ (central venous sample). $\mathrm{NA}$, Not available; $\mathrm{Etco}_{2}$, end-tidal $\mathrm{CO}_{2}$.

${ }^{*} P<.05$ between groups.

$\mathrm{\dagger} P<.05$ within groups.

surgical ASD closure occurred with a decrease in hemoglobin.

Although the decrease in exhaled NO levels after surgical ASD correction with the use of CPB is in agreement with that seen in previous studies, ${ }^{4,7}$ we detected a $23 \%$ increase in exhaled NO after transcatheter ASD closure. This result contrasts with the only other study of exhaled NO after transcatheter ASD closure, in which there was a $22 \%$ decrease in exhaled NO levels. ${ }^{10}$ The reason for the discordance in results is unclear and may reflect differences in exhaled NO sampling techniques (the marked flow dependence of exhaled NO has been demonstrated ${ }^{11}$ ) or anesthetic agents that may impair endothelial function. ${ }^{12} \mathrm{We}$ sampled for $\mathrm{NO}$ with constant ventilator settings: fraction of inspired oxygen between 0.25 and 0.3 and isoflurane (which may impair NO production at concentrations of $>2 \%$ ) kept at $0.5 \%$ to $1 \%$ and discontinued for 15 minutes before sampling. ${ }^{12}$

Pulmonary blood flow is decreased with either surgical or transcatheter ASD closure. The findings in the present study with a decrease in exhaled NO after surgical intervention and an increase after device closure suggest that exhaled NO levels change independently of pulmonary blood flow, at least in patients with atrial level shunts and normal pulmonary artery pressures before and after ASD closure.

We would suggest 2 possible explanations for the increase in exhaled NO after transcatheter ASD closure. First, immediately after ASD closure, pulmonary blood flow decreases, yet pulmonary artery pressures remain relatively unchanged if there are low pulmonary artery pressures before ASD closure. As in the present and other studies, ${ }^{10}$ the calculated pulmonary vascular resistance must increase unless there is recruitment of the pulmonary capillary bed. In the absence of endothelial dysfunction, we suggest that NO production increases in response to either increased pulmonary vascular tone or vascular recruitment. Second, because hemoglobin binds $\mathrm{NO}$ avidly, ${ }^{13}$ a relative paucity in hemoglobin traversing the pulmonary vascular bed caused by an abrupt decrease in pulmonary blood flow would increase free NO levels.

Although high levels of exhaled NO may be measured in the nasopharynx, all of our patients were intubated, and contamination from nasal air was excluded. We minimized the contribution of bronchial NO by sampling with an intra-airway catheter and taking samples during free exhalation to minimize the transit time in the airway and contamination by dead space gas. We verified that inspired NO levels were always lower than expired levels and excluded environmental contamination.

There was a significant difference in exhaled NO levels before ASD closure between the 2 groups. We speculate that this may be related to surgical stimulation before cannulation. However, the consistent change within groups and the increase in exhaled NO in the transcatheter group compared with the decrease in the surgical group suggest that the changes are not due to chance or drift to baseline.

It seems likely that in the present study changes in exhaled NO levels reflect endogenous production by the pulmonary vascular endothelium, as reported in the isolated pig lung and in human subjects during CPB.6,7

In conclusion, surgical ASD closure with $\mathrm{CPB}$ results in a decrease in exhaled NO. Decreased exhaled NO levels may be a marker of pulmonary vascular injury in children undergoing surgical repair of congenital heart defects. Although the origin of postoperative pulmonary vascular complications is complex and multifactorial, decreased NO production may explain the efficacy of inhaled NO therapy of post-CPB pulmonary hypertension and lung injury. Furthermore, exhaled NO levels may prove useful to monitor the effect of strategies to minimize endothelial dysfunction and augment NO production during CPB. In contrast, after transcatheter ASD closure, exhaled NO levels increase, suggesting that alterations in pulmonary blood flow are not primarily responsible for changes in exhaled NO. However, 
after acute reduction in pulmonary blood flow, without a decrease in pressure, there is an increase in NO production.

\section{References}

1. Wessel DL, Adatia I, Giglia TM, Thompson JE, Kulik TJ. Use of inhaled nitric oxide and acetylcholine in the evaluation of pulmonary hypertension and endothelial function after cardiopulmonary bypass. Circulation. 1993;88:2128-38.

2. Schulze-Neick I, Penny DJ, Rigby ML, Morgan C, Kelleher A, Collins $\mathrm{P}$, et al. L-arginine and substance $\mathrm{P}$ reverse the pulmonary endothelial dysfunction caused by congenital heart surgery. Circulation. 1999; 100:749-55.

3. Adatia I, Lillehei C, Arnold JH, Thompson JE, Palazzo R, Fackler JC, et al. Inhaled nitric oxide in the treatment of postoperative graft dysfunction after lung transplantation. Ann Thorac Surg. 1994;57: 1311-8.

4. Beghetti M, Silkoff PE, Caramori M, Holtby HM, Slutsky AS, Adatia I. Decreased exhaled nitric oxide may be a marker of cardiopulmonary bypass-induced injury. Ann Thorac Surg. 1998;66:532-4.

5. McMullan DM, Bekker JM, Parry AJ, Johengen MJ, Kon A, Heidersbach RS, et al. Alterations in endogenous nitric oxide production after cardiopulmonary bypass in lambs with normal and increased pulmonary blood flow. Circulation. 2000;102(suppl 111):172-8.

6. Serraf A, Sellak H, Hervé P, Bonnet N, Robotin M, Detruit H, et al.
Vascular endothelium viability and function after total cardiopulmonary bypass in neonatal piglets. Am J Respir Crit Care Med. 1999; 159:544-51.

7. Ishibe Y, Liu R, Hirosawa J, Kawamura K, Yamasaki K, Saito N. Exhaled nitric oxide level decreases after cardiopulmonary bypass in adult patients. Crit Care Med. 2000;28:3823-7.

8. Cremona G, Higenbottam T, Takao M, Hall L, Bower EA. Exhaled nitric oxide in isolated pig lungs. $J$ Appl Physiol. 1995;78:59-63.

9. Stewart TE, Valenza F, Ribeiro SP, Wener AD, Volgyesi G, Mullen $\mathrm{BM}$, et al. Increased nitric oxide in exhaled gas as an early marker of lung inflammation in a model of sepsis. Am J Respir Crit Care Med. 1995;151:713-8.

10. Tworetzky W, Moore P, Bekker JM, Bristow J, Black SM, Fineman JR. Pulmonary blood flow alters nitric oxide production in patients undergoing device closure of atrial septal defects. J Am Coll Cardiol. 2000;35:463-7.

11. Silkoff P, McClean P, Slutsky A, Furlott H, Hoffstein E, Wakita S, et al. Marked flow-dependence of exhaled nitric oxide using a new technique to exclude nasal nitric oxide. Am J Respir Crit Care Med. 1997; 155:260-7.

12. Nakamura K, Terasako K, Toda H, Miyawaki I, Kakuyama M, Nishiwada M, et al. Mechanisms of inhibition of endothelium-dependent relaxation by halothane, isoflurane, and servoflurane. Can J Anaesth. 1994;41:340-6.

13. Gibson QH, Roughton FJW. The kinetics and equilibria of the reactions of nitric oxide with sheep hemoglobin. J Physiol. 1957;136:50726.

The Journal of Thoracic and Cardiovascular Surgery gives you two tables of contents.

The condensed table of contents tells you at a glance what topics and authors are presented each month. The expanded table of contents gives you a brief abstract of each article. You select only those articles of most interest to you for further reading. 